\title{
Intestinal current measurement versus nasal potential difference measurements for diagnosis of cystic fibrosis: a case-control study
}

\author{
Azadeh Bagheri-Hanson ${ }^{\dagger}$, Sebastian Nedwed ${ }^{\dagger}$, Claudia Rueckes-Nilges and Lutz Naehrlich ${ }^{*}$
}

\begin{abstract}
Background: Nasal potential difference (NPD) and intestinal current measurement (ICM) are functional CFTR tests that are used as adjunctive diagnostic tools for cystic fibrosis (CF). Smoking has a systemic negative impact on CFTR function. A diagnostic comparison between NPD and ICM and the impact of smoking on both CFTR tests has not been done.

Methods: The sweat chloride test, NPD, and ICM were performed in 18 patients with CF (sweat chloride $>60 \mathrm{mmol} / \mathrm{l}$ ), including 6 pancreatic sufficient (PS) patients, and 13 healthy controls, including 8 smokers. The NPD CFTR response to Cl-free and isoproterenol perfusion ( $\left.\triangle \mathrm{OCl}^{-}+\mathrm{Iso}\right)$ was compared to the ICM CFTR response to forskolin/IBMX, carbachol, and histamine ( $\Delta \mathrm{I}_{\mathrm{sC} \text {, forskolin/BMX+ carbachol+histamine) }}$.

Results: The mean NPD CFTR response and ICM CFTR response between patients with CF and healthy controls was significantly different ( $p<0.001$ ), but not between patients with CF who were PS and those who were pancreatic insufficient (PI). Smokers have a decreased CFTR response measured by NPD $(p=0.049)$. For ICM there is a trend towards decreased CFTR response (NS). Three healthy control smokers had NPD responses within the CF-range. In contrast to NPD, there was no overlap of the ICM response between patients with CF and controls.
\end{abstract}

Conclusions: ICM is superior to NPD in distinguishing between patients with CF who have a sweat chloride $>60 \mathrm{mmol} / \mathrm{I}$ and healthy controls, including smokers. Neither NPD nor ICM differentiated between patients with CF who were PS from those who were PI. Smoking has a negative impact on CFTR function in healthy controls measured by NPD and challenges the diagnostic interpretation of NPD, but not ICM.

Keywords: (3-10): Cystic fibrosis, Nasal potential difference, Intestinal current measurement, Sweat chloride, Sweat test, Diagnosis, Smoking

\section{Background}

Cystic fibrosis (CF) is diagnosed based on a defined clinical phenotype and confirmation of cystic fibrosis transmembrane regulator (CFTR) dysfunction, commonly demonstrated by a sweat chloride value of $\geq 60 \mathrm{mmol} / \mathrm{l}$ and/or detection of two CF-causing mutations [1,2]. A small but increasing number of patients present with clinical symptoms characteristic of $\mathrm{CF}$, an intermediate $(30-60 \mathrm{mmol} / \mathrm{l})$ or negative $(\leq 29 \mathrm{mml} / \mathrm{l})$ sweat test, and less than two CF-causing mutations [3-6]. For these

\footnotetext{
* Correspondence: lutz.naehrlich@paediat.med.uni-giessen.de

${ }^{\dagger}$ Equal contributors

Department of Pediatrics, Justus-Liebig-University Giessen, Feulgenstrasse 12, 35385 Giessen, Germany
}

query CF patients, a specific and sensitive CFTR functional test to exclude or confirm a CFTR functional defect characteristic of CF is needed [1,6]. CFTR modulating and correcting drugs have improved CFTR-function in cell cultures [7]. To test their effect in CF-patients, especially those with rare mutations, CFTR-functional tests with low variability and high reproducibility are needed [7].

In addition to sweat testing, two additional CFTR functional tests have been developed over the past 30 years; nasal potential difference (NPD) measurement [8] and intestinal current measurement (ICM) [9]. CFTR function is measured in vivo in the respiratory epithelium by NPD and ex vivo in superficial rectal biopsies by ICM. International standard operating procedures (SOPs) have been 
established for both tests $[8,10]$. Both tests block epithelial sodium channels by amiloride and stimulate cAMPmediated CFTR-mediated chloride transport in chloridefree solution and isoproterenol (NPD) or forskolin and IBMX (ICM). In addition, cholinergic chloride transport is tested by carbachol with ICM. The change after chloridefree and isoproterenol perfusion $\left(\Delta 0 \mathrm{Cl}^{-}+\right.$Iso) with NPD [8] and the sum of the responses after carbachol, forskolin/IBMX ([11]) plus histamine $\left(\Delta \mathrm{I}_{\mathrm{sc}}\right.$, forskolin/IBMX+ carbachol+histamine) with ICM [12] has been proposed to be the best parameter of CFTR function. Both techniques can discriminate CF patients from healthy controls (NPD $[13,14]$; ICM $[11,12,15,16])$, but comparative clinical trials are lacking. Smoking has a systemic negative impact on CFTR-function $[17,18]$, but the impact on the diagnostic aspects of NPD and ICM have not been investigated.

We performed NPD and ICM measurement in CFpatients and healthy controls to determine (1) the ability of these measurements to differentiate CF patients from healthy controls, and (2) the influence of smoking on CFTR function in healthy controls.

\section{Methods}

Between October 2012 and February 2013, 18 patients with CF and 13 healthy controls were recruited at the
Justus-Liebig-University, Giessen, Germany. For this study, the diagnosis of CF was based on at least one clinical manifestation of CF, sweat chloride $\geq 60 \mathrm{mmol} / \mathrm{l}$ and the presence of two CF-causing mutations [1]. Pancreatic sufficiency (PS) was defined as fecal elastase $>100 \mu \mathrm{g} / \mathrm{g}$ stool. Healthy controls had no clinical manifestation of CF and a sweat chloride value $<60 \mathrm{mmol} / \mathrm{l}$ (Non-CF). Smoking was defined as any active or passive exposure to tobacco smoke. Exclusion criteria were participation in another medical clinical trial during the past 30 days, acute respiratory symptoms, intake of ivacaftor, known hemorrhoids, or bleeding diathesis. The ethics committee of the Justus-Liebig-Universität Giessen approved the protocol (AZ109/12). The study was performed in accordance with the declaration of Helsinki. Written informed consent was obtained from each participant aged 18 years and older. For participants younger than 18 years of age, written informed consent was obtained from each participant's parents or legal guardian, and age-appropriate consent was obtained from each participant. The sweat test, NPD, and ICM were performed on the same day for each subject.

The sweat test was performed according to Clinical and Laboratory Standards Institute guidelines [19]. For sweat stimulation and collection, the Macroduct ${ }^{\oplus}$ system (Wescor,

Table 1 Characteristics and CFTR response of pancreatic insufficient (CF-PI) and pancreatic sufficient (CF-PS) patients with CF and controls

\begin{tabular}{|c|c|c|c|c|}
\hline & CF-PI $(n=12)$ & CF-PS $(n=6)$ & CF-all $(n=18)$ & Controls $(n=13)$ \\
\hline \multirow[t]{2}{*}{ Age, years } & $24.0 \pm 6.1$ & $23.3 \pm 11.8$ & $22.8 \pm 8.0$ & $30.6 \pm 10.4$ \\
\hline & $22.0(19.0-26.0)$ & $16.0(14.5-30.5)$ & $20.5(18.3-25.3)$ & $25.0(23.5-35.5)$ \\
\hline Gender, females:males & $3: 9$ & $5: 1$ & $8: 10$ & $7: 6$ \\
\hline \multirow[t]{2}{*}{ Body mass index Z-score } & $-1.18 \pm 0.80$ & $-0.62 \pm 1,41$ & $-0.99 \pm 1.03^{*}$ & $0.00 \pm 0.65^{*}$ \\
\hline & $-1.05(-2.40-0.00)$ & $1.41(-0.20-0.70)$ & $-0.90(-2.60-0.70)$ & $0.00(-1.10-1.30)$ \\
\hline \multirow[t]{2}{*}{ Sweat chloride $(\mathrm{mmol} / \mathrm{l})$} & $110 \pm 13^{* *}$ & $86 \pm 14^{* *}$ & $102 \pm 17^{*}$ & $19 \pm 8^{*}$ \\
\hline & $106(92-140)$ & $90(70-99)$ & $104(70-140)$ & $19(10-36)$ \\
\hline \multirow{2}{*}{$\begin{array}{l}\text { NPD CFTR response } \\
\text { average } \Delta 0 \mathrm{Cl}^{-}+\mathrm{Iso}(\mathrm{mV})\end{array}$} & $4.6 \pm 3.9$ & $1.5 \pm 4.1$ & $3.6 \pm 4.1^{*}$ & $-13.6 \pm 8.5^{*}$ \\
\hline & $5.1(-3.0-11.9)$ & $1.5(-3.2-6.23)$ & $4.5(-3.2-11.9)$ & $-12.7(-26.4--1.92)$ \\
\hline \multirow{2}{*}{$\begin{array}{l}\text { ICM CFTR response } \\
\text { average } \Delta \mathrm{lsc}\left(\mu \mathrm{A} / \mathrm{cm}^{2)}\right) \\
\text { (forskolin/IBMX }+ \text { carbachol + histamine) }\end{array}$} & $-0.3 \pm 8.1$ & $5.3 \pm 10.9$ & $1.6 \pm 9.2^{*}$ & $77.8 \pm 34.8^{*}$ \\
\hline & $-0.6(-12.6-17.9)$ & $5.0(-9.7-19.0)$ & $0.1(-12.6-19.0)$ & $65.3(39.6-140.9)$ \\
\hline \multirow[t]{6}{*}{ Genotyping } & F508/F508 (6x) & F508/R347P (2X) & & $148 \mathrm{~T} / \mathrm{R} 117 \mathrm{H}-7 \mathrm{~T}$ \\
\hline & F508/G551D (2X) & $\mathrm{F} 508 / 3849+10 \mathrm{~kb} \mathrm{C}->\mathrm{T}(2 \mathrm{x})$ & & F508/- \\
\hline & F508/G542X & F508/R334W & & $--/--$ \\
\hline & F508/N1303K & $\mathrm{F} 508 / ?$ & & $\mathrm{ND} / \mathrm{ND}(11)$ \\
\hline & $\mathrm{F} 508 / 1248+1 \mathrm{G}-\mathrm{A}$ & & & \\
\hline & F508/dele 14a,15,16,17a,17b & & & \\
\hline
\end{tabular}


Inc., Logan, USA) was used. Chloride was measured by chloride titration. A sweat chloride level $\geq 60 \mathrm{mmol} / \mathrm{l}$ was interpreted as within the CF range, $30-60 \mathrm{mmol} / \mathrm{l}$ as equivocal, and $\leq 29 \mathrm{mmol}$ as normal [1].

NPD was performed by one operator who was accredited by the Cystic Fibrosis Foundations' (CFF) Therapeutic Developments Network (TDN), and followed the CFF TDN SOP (version: January 2009) [8]. We used terbutaline as a substitute for isoproterenol in accordance with the SOP. The chloride-free and isoproterenol response $\left(\triangle 0 \mathrm{Cl}^{-}+\mathrm{Iso}\right)$ (NPD CFTR response) and the Wilschanksi score (defined as $\mathrm{e}^{\text {(response to chloride-free and }}$ isoproterenol/response to amiloride) ) [20] representing the CFTR response were calculated as the average or best result from both nostrils. The $\Delta 0 \mathrm{Cl}^{-}+$Iso was interpreted as normal when $<-12 \mathrm{mV}$, as in the CF range when $>-7.7 \mathrm{mV}$, and as equivocal for results between -12 and $-7.7 \mathrm{mV}$ [6]. The Wilschanski score was interpreted as normal $(<0.65)$, in the CF-range (>0.70), or equivocal $(0.65-0.70)$ [20]. If the mean $\Delta \mathrm{OCl}^{-}+$Iso was $>-7.7 \mathrm{mV}$ in healthy controls, the NPD was repeated on a different day. Only the measurement with the highest $\Delta 0 \mathrm{Cl}^{-}+$Iso was reported. If both measurements confirmed a $\Delta 0 \mathrm{Cl}^{-}+$Iso in the CF range, CFTR genotyping (sequencing and multiplex ligation- dependent probe amplification) was offered as part of the participant's clinical care and reported as part of the baseline data. Genotyping of all healthy controls was not ethically approved.

The ICM followed the European Cystic Fibrosis SocietyTherapeutic Development Network (ECFS-TDN) SOP (V2.7; Oct 26, 2011), which is based on the Rotterdam protocol. The tissues sliders (P2407C [1.5 mm diameter aperture slider; area $0,018 \mathrm{~cm}^{2}$ ] or P2407B [1.2 mm diameter aperture slider; area $\left.0.011 \mathrm{~cm}^{2}\right]$; Physiologic Instruments, San Diego, USA) were mounted without tissue in the chambers (4-chamber system [EM-LVSYS-4; Physiologic Instrument, San Diego, USA]), which were filled on both sides with $2 \mathrm{ml}$ Meyler buffer solution $(10 \mathrm{mM}$ Hepes; $0.3 \mathrm{mM} \mathrm{Na} \mathrm{HPO}_{4} ; 0.4 \mathrm{mM} \mathrm{NaH} \mathrm{PO}_{4} ; 1.0 \mathrm{mM}$ $\mathrm{MgCl}_{2} ; 1.3 \mathrm{mM} \mathrm{CaCl} ; 4.7 \mathrm{mM} \mathrm{KCl} ; 128 \mathrm{mM} \mathrm{NaCl}$; $20.2 \mathrm{mM} \mathrm{NaHCO} ; 10 \mathrm{mM}$ D-Glucose; $0.01 \mathrm{mM}$ indomethacin; pH 7.4; osmolarity 300 mOsm). PowerLab (4/30; ADInstruments Ltd., Dunedin, New Zealand) and Labchart ${ }^{\oplus}$ software (release 7.2; ADInstruments Ltd., Dunedin, New Zealand) were used for data acquisition. A stable open Potential Difference (PD) was ensured and an input offset to $0 \mathrm{mV}$ was performed. Fluid resistance compensation was performed by applying short current pulses

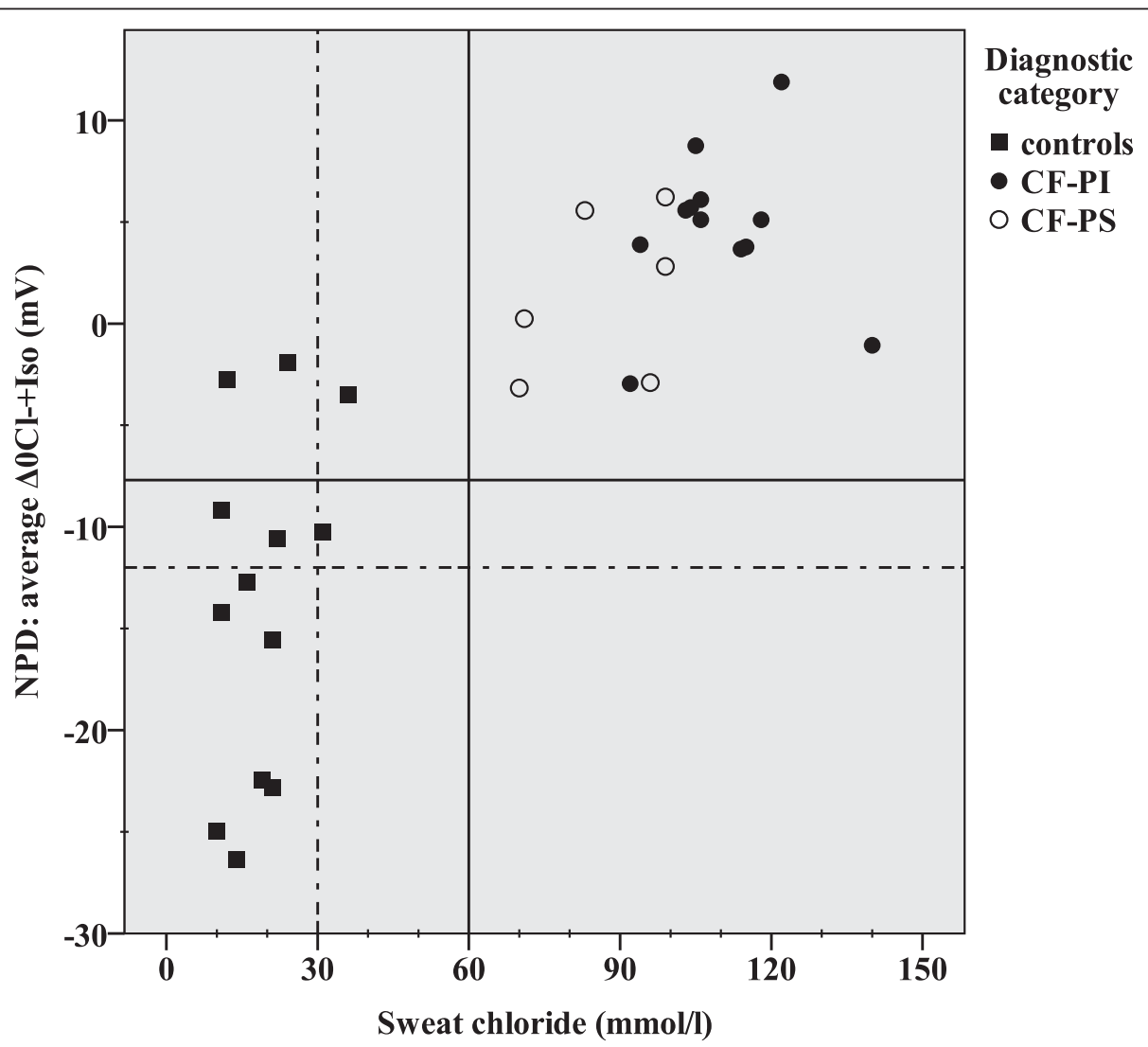

Figure 1 Correlation of average $\mathbf{\Delta} \mathbf{C C l}^{-}+$Iso (NPD) and sweat chloride. The normal range is indicated for values below and left of the dotted lines, and the intermediate range is shown between the solid and dotted lines. 
$(15 \mu \mathrm{A})$ by the VCC MC4S Multi-Channel Voltage Current Clamp (Physiologic Instrument, San Diego, USA) and adjusting the fluid resistance.

For ICM, at least 4 superficial rectal biopsies were obtained by suction biopsies (aspiration biopsy instrument according to Wilital (UE7605); ulrich GmbH, Ulm, Germany) without prior bowel preparation. Biopsies were immediately stored in ice-cold buffer solution (Dulbecco's phosphate buffered saline and indomethacin, final concentration $10 \mu \mathrm{M})$ and mounted on adequate tissue sliders. After mounting the sliders in the heated and slightly sparged $\left(95 \% \mathrm{O}_{2} / 5 \% \mathrm{CO}_{2}\right)$ 4-chamber system, each basal resistance was measured by applying short current pulses $(15 \mu \mathrm{A})$ and registering the corresponding change in $\mathrm{V}_{\mathrm{t}}$ (typical range 15-30 Ohm $\times \mathrm{cm}^{2}$ ) with the VCC MC4S Multi-Channel Voltage Current Clamp (Physiologic Instrument, San Diego, USA). After that the voltage was clamped at $0 \mathrm{mV}$ and the raw short circuit current $\left({ }_{\mathrm{r}} \mathrm{I}_{\mathrm{sc}}\right)$ was recorded from then on. Due to different sliders with different areas (P2407C [1.5 mm diameter aperture slider; area $0.018 \mathrm{~cm}^{2}$ ] or P2407B [1.2 $\mathrm{mm}$ diameter aperture slider; area $\left.0.011 \mathrm{~cm}^{2}\right]$ ); Physiologic Instruments, San Diego, USA), the raw ${ }_{r} \mathrm{I}_{\mathrm{sc}}$ was converted to $\mathrm{I}_{\mathrm{sc}}(\mu \mathrm{A} /$ $\mathrm{cm}^{2}$ ). After applying $100 \mu \mathrm{M}$ carbachol (which stimulates cholinergic $\mathrm{Cl}^{-}$secretion by opening basolateral
$\mathrm{K}^{+}$channels) to the serosal compartment, an $\mathrm{I}_{\mathrm{sc}}$ response was evoked for quality control of the biopsy. After a 40-min equilibration in Meyler buffer, the basal $\mathrm{I}_{\mathrm{sc}}$ was noted and $2 \mu \mathrm{l}$ amiloride (to block amiloride-sensitive sodium channels) was added to the mucosal compartment. After $5 \mathrm{~min}$ or when the $\mathrm{I}_{\mathrm{sc}}$ was stable, $10 \mu \mathrm{M}$ forskolin and $100 \mu \mathrm{M}$ IBMX (to stimulate cAMPdependent CFTR- $\mathrm{Cl}^{-}$transport) were added to the mucosal and serosal compartments $\left(\Delta \mathrm{I}_{\mathrm{sc}}\right.$, forskolin/IBMX $)$. After a minimum of $10 \mathrm{~min}, 10 \mu \mathrm{M}$ genisteine (CFTR-potentiator) was added to both compartments. After a minimum of $5 \mathrm{~min}, 100 \mu \mathrm{M}$ carbachol was added to the serosal compartment $\left(\Delta \mathrm{I}_{\mathrm{sc}}\right.$, carbachol $)$. After a minimum of $10 \mathrm{~min}, 200 \mu \mathrm{M}$ 4,4' -Diisothiocyano-2,2' -stilbenedisulfonic acid (DIDS) (blocking non-CFTR- $\mathrm{Cl}^{-}$channels) was added to the mucosal compartment. After $10 \mathrm{~min}, 500$ $\mu \mathrm{M}$ histamine (to stimulate $\mathrm{Ca}^{2+}$ and proteinkinase Cmediated CFTR $\mathrm{Cl}^{-}$secretion) was added to the serosal compartment $\left(\Delta \mathrm{I}_{\mathrm{sc}}\right.$, histamine $)$. In the open circuit, the final transepithelial voltage and final resistance were measured by applying short current pulses as in the beginning. Preliminary data suggested that the average $\Delta \mathrm{I}_{\mathrm{sc}}$, forskolin/IBMX+ carbachol+histamine is the best diagnostic ICM parameter for chloride secretory response (ICM CFTR response), but reference ranges have not been established [10].

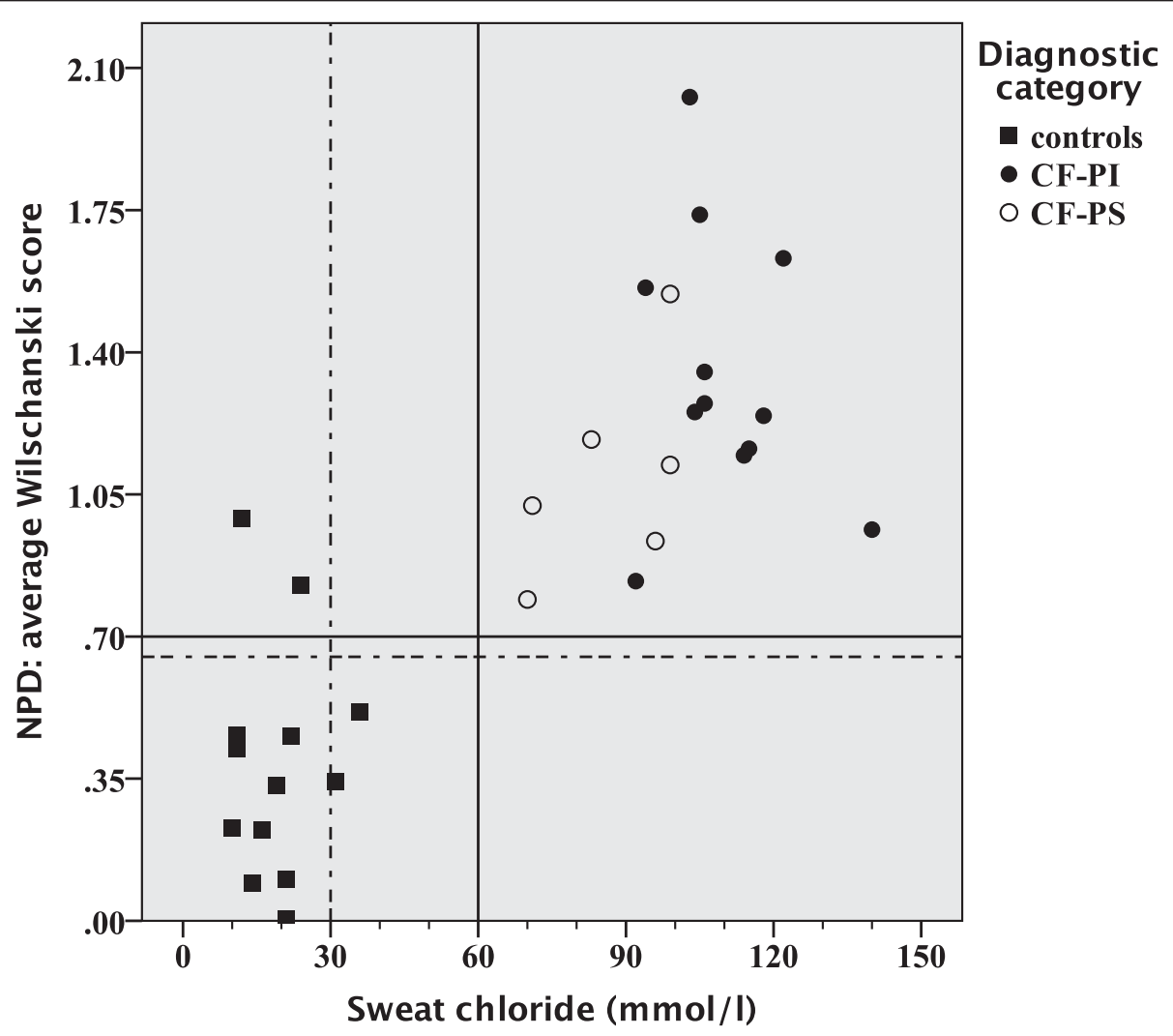

Figure 2 Correlation of the average Wilschanski score (NPD) and sweat chloride. The normal range is shown below and left of the dotted lines, and the intermediate range is shown between the solid and dotted lines. 
Data are presented as the mean \pm standard deviation (SD) (normally distributed variables), respective the median values, and 25th and 75th percentiles (nonnormally distributed variables). Group comparisons were performed using the Student's t test or Mann-Whitney $\mathrm{U}$ test for normally or non-normally distributed variables, respectively. Statistical significance was defined as $p<0.05$. All analyses were performed with IBM SPSS Statistics 21 (release 21; IBM, Armonk, USA).

\section{Results}

Our study included 18 patients with CF and 13 healthy controls with a median age of 20.5 and 25.0 years, respectively (NS) (Table 1). As consequence of our inclusion criteria, sweat chloride values distinguish patients with CF from healthy controls $(\mathrm{p}<0.001)$. Although the mean sweat chloride differed between CF-PS and CF-PI patients $(\mathrm{p}=0.003)$, an individual overlap occurs (Table 1 , Figure 1). The mean NPD CFTR response significantly discriminated between $\mathrm{CF}$ patients and healthy controls ( $\mathrm{p}<0.001$ ), but not between patients with CF who were PS versus PI (Table 1). Four healthy controls had an average $\Delta 0 \mathrm{Cl}^{-}+$Iso of $>-7.7 \mathrm{mV}$. Three out of four controls had a repeatable average NPD CFTR response in the CF-range for $\Delta 0 \mathrm{Cl}^{-}+$Iso $>-7.7 \mathrm{mV}$ (23\% of all healthy controls) (Figure 1), and two additional controls when using the Wilschanski score (15\% of all healthy controls) (Figure 2). All these healthy controls were smokers. CFTR genotyping was offered to these three healthy controls as part of clinical routine and none had two CF-causing mutations (Table 1). For ICM a median of 6 (5-7) rectal biopsies were sampled per patient without severe adverse events. The mean ICM CFTR response was significantly different between CF patients and healthy controls $(\mathrm{p}<0.001)$, but not between patients with CF who were PS versus those who were PI (Table 1). We could not detect any age-dependency of the response to Isoproterenol/Forskolin. In contrast to NPD, there was no overlap between CF-patients and controls (Figures 3 and 4). Using the best instead of the average NPD, the CFTR response overlap did not change (Additional file 1). Using the best instead of the average ICM, the CFTR response resulted in one overlap (Additional file 2).

In healthy controls, smoking had no influence on sweat chloride (NS), but decreased CFTR function as measured by NPD $(\mathrm{p}=0.049)$ (Table 2 and Figure 5$)$,

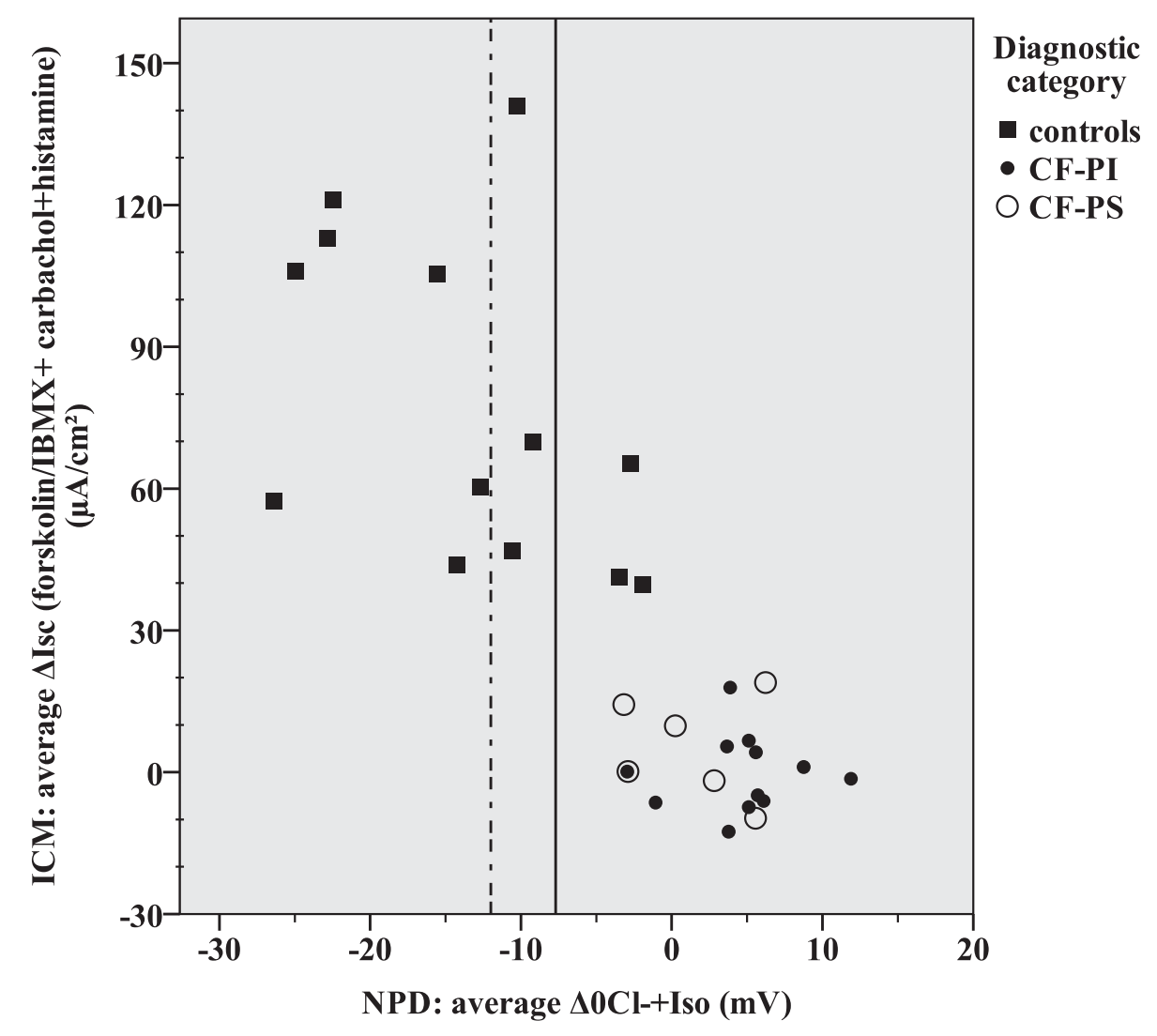

Figure 3 Correlation between the average $\Delta \mathrm{Isc}$ (forskolin/IBMX + carbachol + histamine) (ICM) and average $\Delta 0 \mathrm{Cl}^{-}+\mathrm{Iso}$ (NPD).

The normal range is shown left of the dotted line. The intermediate range is shown between the solid and dotted lines. A higher $\Delta$ lsc (forskolin/ IBMX + carbachol + histamine) represents a better CFTR response. 


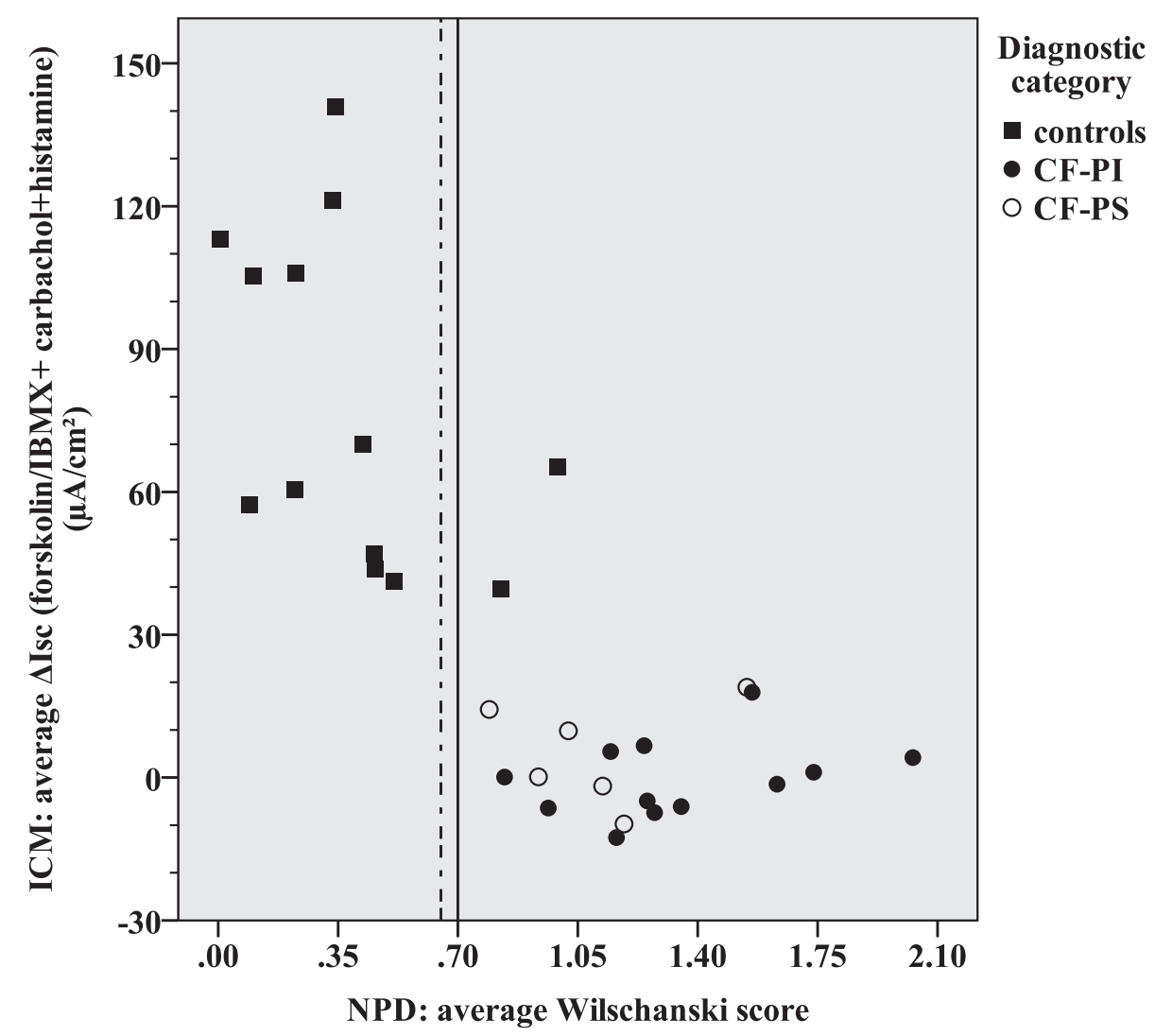

Figure 4 Correlation between the average $\triangle$ Isc (forskolin/IBMX + carbachol + histamine) (ICM) and average Wilschanski score (NPD). The normal range is shown left of the dotted line. The intermediate range is shown between the solid and dotted lines. A higher $\Delta$ lsc (forskolin/ IBMX + carbachol + histamine) represents a better CFTR-response.

and resulted in intermediate or even abnormal NPD results, but not ICM or sweat chloride results. There is a trend in ICM measurements indicative that smoking might not only affect CFTR in the respiratory tract, but also in the intestine (Table 2 and Figure 6).

\section{Discussion}

ICM is superior to NPD for distinguishing between CF patients with a sweat chloride $>60 \mathrm{mmol} / \mathrm{l}$ and healthy

Table 2 Influence of smoking (active and/or passive) in healthy controls on NPD and ICM CFTR responses

\begin{tabular}{|c|c|c|c|}
\hline & $\begin{array}{c}\text { Nonsmokers } \\
n=5\end{array}$ & $\begin{array}{c}\text { Smokers } \\
\mathrm{n}=\mathbf{8}\end{array}$ & $p$-value \\
\hline Sweat chloride (mmol/L) & $18 \pm 8$ & $20 \pm 9$ & NS \\
\hline NPD CFTR response & $-19.3 \pm 7.4$ & $-10.1 \pm 7.3$ & 0.049 \\
\hline \multicolumn{4}{|l|}{ Average $\Delta \mathrm{OCl}^{-}+\mathrm{Iso}(\mathrm{mV})$} \\
\hline ICM CFTR response & $97.2 \pm 37.1$ & $65.7 \pm 29.1$ & NS \\
\hline \multicolumn{4}{|l|}{ Average $\Delta \mathrm{Isc}\left(\mu \mathrm{A} / \mathrm{cm}^{2}\right)$} \\
\hline $\begin{array}{l}\text { (forskolin/IBMX + carbachol + } \\
\text { histamine) }\end{array}$ & & & \\
\hline
\end{tabular}

All values are shown as the mean \pm standard deviation. controls, including smokers. Neither NPD nor ICM diffe rentiated patients with CF who were PS from those who were PI. Smoking has a negative impact on CFTR function in healthy controls measured by NPD, and challenges the diagnostic interpretation of NPD. There is a trend in ICM indicative that smoking might not only affect CFTR in the respiratory tract, but also in the intestine, which has no impact on diagnostic interpretation.

NPD has been used as a diagnostic test for CF since the late 1980s $[14,21,22]$. Studies have shown $94.8-100 \%$ sensitivity and $96.5-100 \%$ specificity of $\Delta 0 \mathrm{Cl}^{-}+$Iso for separating PI patients with CF from healthy controls $[13,14,23]$. Experience with a broader spectrum of patients with $\mathrm{CF}$ $[24,25]$ and equivocal patients (sweat chloride $<60 \mathrm{mmol} / \mathrm{l}$ and less than two CF-causing mutations) [20] described a clinically relevant overlap for $\Delta 0 \mathrm{Cl}^{-}+$Iso. Even in F508del homozygous patients, a residual CFTR NPD response with [26] or without $[27,28]$ an observed clinical difference has been described. Some centers introduced an intermediate category for $\Delta 0 \mathrm{Cl}^{-}+$Iso [6], interpret the highest NPD CFTR response [29], or use a composite score that includes sodium and chloride conductance [20,30]. Irrespective of the diagnostic criteria, our result showed a clinically 


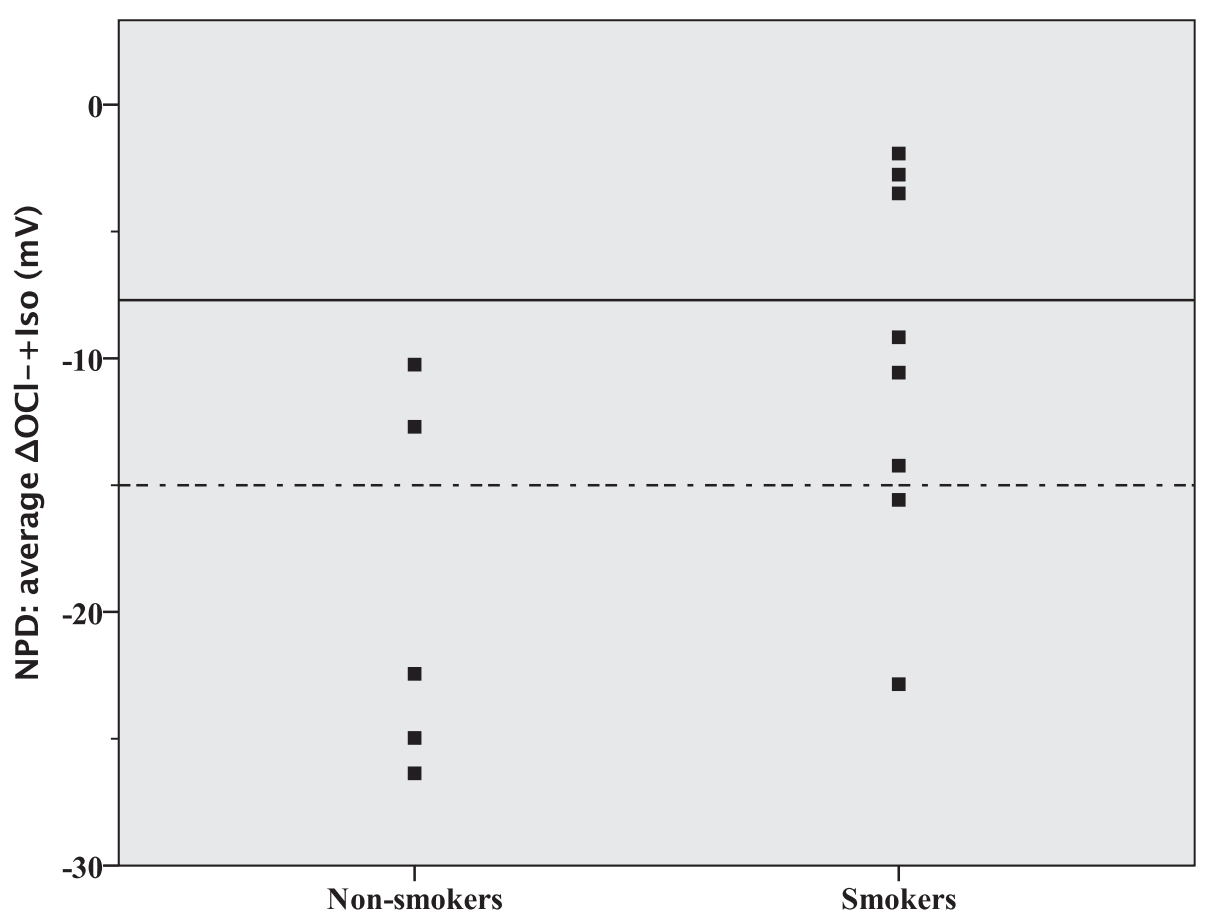

Figure 5 Average $\Delta \mathrm{OCl}^{-}+$Iso (NPD) in healthy controls according to smoking status. The normal range is shown below the dotted line and the intermediate range is shown between the solid and dotted lines.

relevant overlap between patients with $\mathrm{CF}$ and healthy controls. A normal average NPD CFTR response excludes CF, but an abnormal average NPD CFTR response could occur in healthy controls, especially in smokers, and can lead to a false-positive diagnosis of CF. A repeated measurement of a pathologic NPD response reduced the falsepositive results in 1 out of 4 healthy controls in our cohort and should be recommended as a standard approach.

ICM was developed as a research tool for CFTR function in the 1990s [31] and has been used as a diagnostic test since the early 2000s [15,32]. Two different protocols are established; the Freiburg protocol [9] and the original [33] and adapted [34] Rotterdam protocol. We used the newest ECFS-ICM-SOP, which is an adapted Rotterdam protocol. The combination of cAMP-mediated $\mathrm{Cl}^{-}$ secretion, and the carbachol and histamine (Rotterdam protocol) responses separate patients with $\mathrm{CF}$ from those without CF $[11,12,34]$, but not patients with CF who are PS from those who are PI [11,12], which is in accordance with our results. The $50 \%$ loss of CFTR protein in CF heterozygotes could not be detected by ICM [35] independent of the protocol $[15,32]$. For the Rotterdam protocol, De Jonge postulated that the ICM response is not proportional to the CFTR amount in the apical membrane of coloncytes except at a low level $(<10-15 \%)$ and could therefore only detect an 80-85\% loss of CFTR expression/ function [32]. Therefore, mild mutations could result in a false-negative ICM. Interestingly, Derichs reported 8 patients with a sweat chloride $>60 \mathrm{mmol} / \mathrm{l}$, fewer than two CF-causing mutations after sequencing, and a normal ICM response who were judged as CF unlikely [12]. Our results with the new ECFS-ICM SOP confirm the high predictive value and practicability of this adapted ICM Rotterdam protocol.

Our data suggest that NPD is more likely to detect CFTR dysfunction in healthy controls than the ICM or sweat test. This could be explained by tissue specific differences in CFTR expression, alternative chloride channel expression, or extrinsic factors. Kälin et al. showed identical CFTR expression in the respiratory and intestinal tract of F508del-homozygous patients and healthy controls [36]. Highly variable CFTR expression in the nose [37] and colon [38] of F508del homozygous patients has been described, varying from $0-100 \%$ [37]. Therefore, in the respiratory and intestinal tract, individual CFTR expression seems to be more relevant than tissue specific expression. Alternative chloride channels could contribute to the chloride conductance, but have not been described in the distal colon [39]. Furthermore, previous infections [40], milder trauma [14], smoking [17], increased paracellular permeability [41], and decreased CFTR expression [42] and CFTR response [43]. With the exception of smoking, these extrinsic factors are relevant only for NPD, but not for rectal biopsies [44]. Smoking causes a decreased NPD response [17], but although a decreased systemic CFTR function mediated by acrolein [18]. Raju et al. demonstrated a $65 \%$ decrease in 


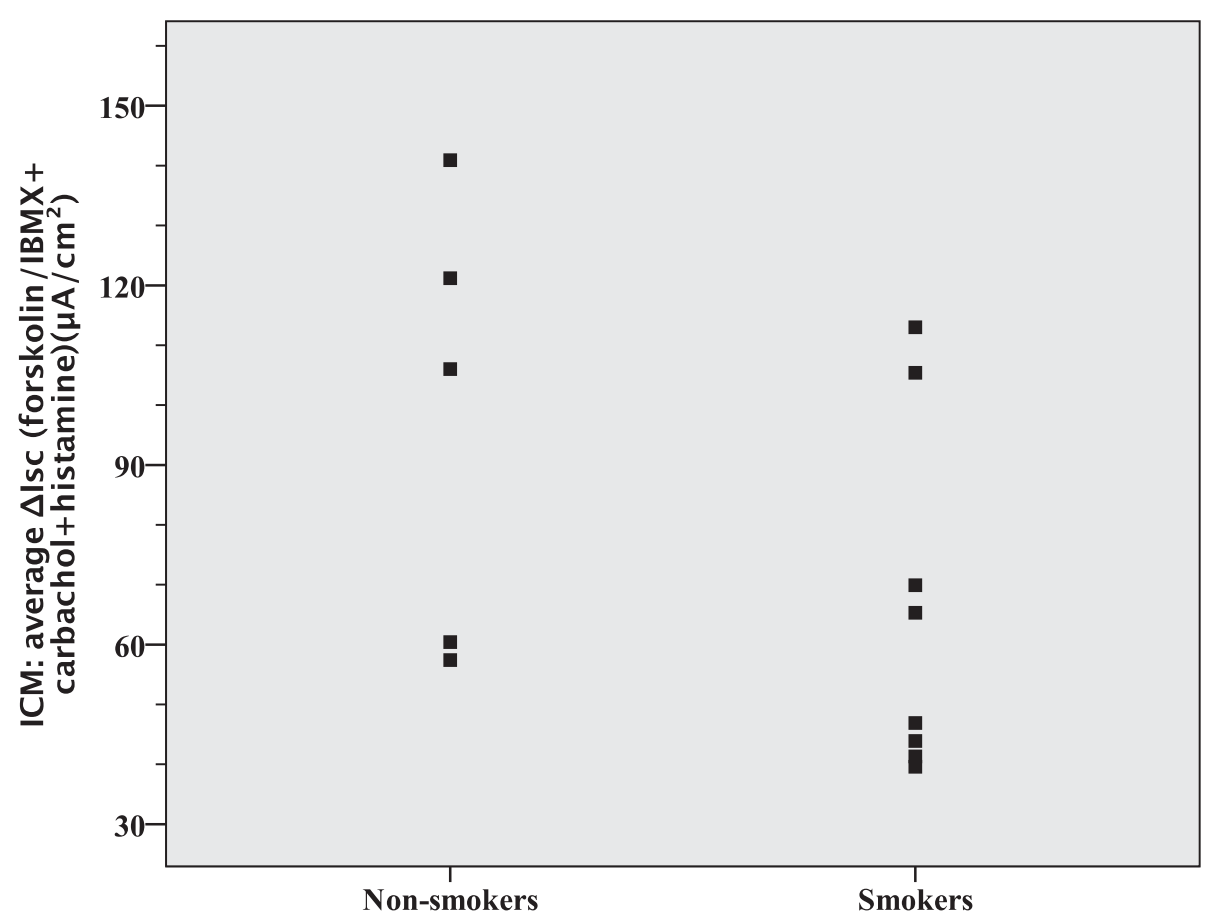

Figure 6 Average $\Delta$ Isc (forskolin/IBMX + carbachol + histamine) (ICM) in healthy controls according to smoking status. A higher $\Delta \mathrm{lsC}$ (forskolin/IBMX + carbachol + histamine) represents a better CFTR response.

the ICM CFTR response in healthy smokers compared with non-smokers [18]. Our results confirm these findings. In contrast to NPD, smoking did not influence the diagnostic cut-off for ICM in our cohort. Therefore, ICM seems to be a more robust diagnostic test than NPD to distinguish primary from secondary CFTR dysfunction. This is important for the interpretation of NPD as an adjunctive diagnostic test in patients with query-CF who are exposed to smoking.

Limitations of our study include the small number of participants in each group, the lack of patients with CF with a sweat chloride value $<60 \mathrm{mmol} / \mathrm{l}$, and patients with congenital bilateral absence of the vas deferens (CBAVD). The strength of our study is the genotyping of healthy controls with an abnormal CFTR NPD response, and the use of standardized protocols for sweat testing, NPD, and ICM.

\section{Conclusions}

From our results, a normal average NPD CFTR response excludes CF, but an intermediate or abnormal NPD CFTR response could be detected in healthy controls. NPD should be judged carefully, especially in patients with chronic rhinosinusitis and exposure to smoking. ICM combined with cAMP-mediated and cholinergic $\mathrm{Cl}$ secretion seems to be a practicable diagnostic test with an increased specificity compared with NPD. Discordant results of both CFTR functional tests could be detected and challenge the diagnostic interpretation. Larger study groups that include smokers and patients with CBAVD or CF with a sweat chloride between $30-60 \mathrm{mmol} / \mathrm{l}$ are needed to confirm our results.

\section{Additional files}

Additional file 1: Correlation of the best and average $\Delta \mathrm{OCl}^{-}+\mathrm{Iso}$ (NPD). The normal range is shown below and left of the dotted lines. The intermediate range is shown between the solid and dotted lines.

Additional file 2: Correlation of the best and average $\Delta \mathrm{lsC}$ (forskolin/IBMX + carbachol + histamine) (ICM). A higher $\Delta \mathrm{IsC}$ (forskolin/IBMX + carbachol + histamine) represents a better CFTR response.

\section{Competing interests}

The authors declare that they have no competing interests.

\section{Authors' contributions}

$\mathrm{ABH}$ recruited participants, performed the rectal biopsies, supported the NPD measurements, and helped draft the manuscript. SN recruited participants, performed the ICM measurements, and helped draft the manuscript. CRN supported the NPD measurements, performed the ICM measurements, and helped draft the manuscript. LN conceived the study, recruited participants, performed the rectal biopsies and statistical analysis, and drafted the manuscript. All authors read and approved the final manuscript.

\section{Acknowledgements}

The authors would like to thank the patients with CF and healthy controls; Kai Haus, Gießen, Germany, for technical support; Cornelia Kraus, FriedrichAlexander University, Erlangen, Germany, for genotyping; and the Mukoviszidose Förderverein Gießen e.V, Gießen, Germany, for financial support.

Received: 18 June 2014 Accepted: 29 September 2014 Published: 4 October 2014 


\section{References}

1. De Boeck K, Wilschanski M, Castellani C, Taylor C, Cuppens H, Dodge J, Sinaasappel M: Cystic fibrosis: terminology and diagnostic algorithms. Thorax 2006, 61(7):627-635.

2. Farrell PM, Rosenstein BJ, White TB, Accurso FJ, Castellani C, Cutting GR, Durie PR, Legrys VA, Massie J, Parad RB, Rock MJ, Campbell PW 3rd: Guidelines for diagnosis of cystic fibrosis in newborns through older adults: cystic fibrosis foundation consensus report. J Pediatr 2008, 153(2):S4-S14.

3. Gonska T, Choi P, Stephenson A, Ellis L, Martin S, Solomon M, Dupuis A, Dorfman R, Zielenski J, Ooi CY, Weiser W, Durie PR, Tullis E: Role of cystic fibrosis transmembrane conductance regulator in patients with chronic sinopulmonary disease. Chest 2012, 142(4):996-1004.

4. Ooi CY, Dupuis A, Ellis L, Jarvi K, Martin S, Ray PN, Steele L, Kortan P, Gonska T, Dorfman R, Solomon M, Zielenski J, Corey M, Tullis E, Durie P: Does extensive genotyping and nasal potential difference testing clarify the diagnosis of cystic fibrosis among patients with single-organ manifestations of cystic fibrosis? Thorax 2014, 69(3):254-260.

5. Segal I, Yaakov Y, Adler SN, Blau H, Broide E, Santo M, Yahav Y, Klar A, Lerner A, Aviram M, Ellis I, Mountford R, Shteyer E, Kerem E, Wilschanski M: Cystic fibrosis transmembrane conductance regulator ion channel function testing in recurrent acute pancreatitis. J Clin Gastroenterol 2008, 42(7):810-814.

6. Ooi CY, Dupuis A, Ellis L, Jarvi K, Martin S, Gonska T, Dorfman R, Kortan P, Solomon M, Tullis E, Durie PR: Comparing the American and European diagnostic guidelines for cystic fibrosis: same disease, different language? Thorax 2012, 67(7):618-624.

7. De Boeck K, Kent L, Davies J, Derichs N, Amaral M, Rowe SM, Middleton P, de Jonge H, Bronsveld I, Wilschanski M, Melotti P, Danner-Boucher I, Boerner S, Fajac I, Southern K, de Nooijer RA, Bot A, de Rijke Y, de Wachter E, Leal T, Vermeulen F, Hug MJ, Rault G, Nguyen-Khoa T, Barreto C, Proesmans M, Sermet-Gaudelus I: CFTR biomarkers: time for promotion to surrogate end-point. Eur Respir J 2013, 41(1):203-216.

8. Rowe SM, Clancy JP, Wilschanski M: Nasal potential difference measurements to assess CFTR ion channel activity. Methods Mol Biol 2011, 741:69-86.

9. Hug MJ, Derichs N, Bronsveld I, Clancy JP: Measurement of ion transport function in rectal biopsies. Methods Mol Biol 2011, 741:87-107.

10. Derichs N, Pinders-Kessler L, Bronsveld I, Scheinert S, Rückes-Nilges C, de Jonge H, Nährlich L: Multicenter European Standardization and reference values for intestinal current measurement in rectal biopsies. Pediatr Pulmonol 2013, 48(\$36):300.

11. Sousa M, Servidoni MF, Vinagre AM, Ramalho AS, Bonadia LC, Felicio V, Ribeiro MA, Uliyakina I, Marson FA, Kmit A, Cardoso SR, Ribeiro JD, Bertuzzo CS, Sousa L, Kunzelmann K, Ribeiro AF, Amaral MD: Measurements of CFTR-mediated $\mathrm{Cl}$ - secretion in human rectal biopsies constitute a robust biomarker for Cystic Fibrosis diagnosis and prognosis. PLoS One 2012, 7(10):e47708.

12. Derichs N, Sanz J, Von Kanel T, Stolpe C, Zapf A, Tummler B, Gallati S, Ballmann M: Intestinal current measurement for diagnostic classification of patients with questionable cystic fibrosis: validation and reference data. Thorax 2010, 65(7):594-599.

13. Liu B, Hathorne H, Hill A, Cohen M: J. B., Solomon MG, Calancy JP, Rowe SM: Normative values and receiver operating characteristics of NPD for diagnostic measurements. Pediatr Pulmonol 2010, 303(S33):307.

14. Knowles MR, Paradiso AM, Boucher RC: In vivo nasal potential difference: techniques and protocols for assessing efficacy of gene transfer in cystic fibrosis. Hum Gene Ther 1995, 6(4):445-455.

15. Hirtz S, Gonska T, Seydewitz HH, Thomas J, Greiner P, Kuehr J, Brandis M, Eichler I, Rocha H, Lopes Al, Barreto C, Ramalho A, Amaral MD, Kunzelmann $\mathrm{K}$, Mall $\mathrm{M}$ : CFTR Cl- channel function in native human colon correlates with the genotype and phenotype in cystic fibrosis. Gastroenterology 2004, 127(4):1085-1095.

16. Cohen-Cymberknoh M, Yaakov Y, Shoseyov D, Shteyer E, Schachar E, Rivlin J, Bentur L, Picard E, Aviram M, Israeli E, Kerem E, Wilschanski M: Evaluation of the intestinal current measurement method as a diagnostic test for cystic fibrosis. Pediatr Pulmonol 2013, 48(3):229-235.

17. Cantin AM, Hanrahan JW, Bilodeau G, Ellis L, Dupuis A, Liao J, Zielenski J, Durie P. Cystic fibrosis transmembrane conductance regulator function is suppressed in cigarette smokers. Am J Respir Crit Care Med 2006, 173(10):1139-1144.

18. Raju SV, Jackson PL, Courville CA, McNicholas CM, Sloane PA, Sabbatini G, Tidwell S, Tang LP, Liu B, Fortenberry JA, Jones CW, Boydston JA, Clancy JP, Bowen LE, Accurso FJ, Blalock JE, Dransfield MT, Rowe SM: Cigarette smoke induces systemic defects in cystic fibrosis transmembrane conductance regulator function. Am J Respir Crit Care Med 2013, 188(11):1321-1330.
19. Clinical and Laboratory Standards Institute: Sweat Testing: Sample Collection and Quantitative Chloride Analysis; Approved Guideline-Third Edition, Volume CLSI document C34-A3. Wayne, PA, USA: Clinical and Laboratory Standards Institute; 2009.

20. Wilschanski M, Famini H, Strauss-Liviatan N, Rivlin J, Blau H, Bibi H, Bentur L, Yahav Y, Springer H, Kramer MR, Klar A, llani A, Kerem B, Kerem E: Nasal potential difference measurements in patients with atypical cystic fibrosis. Eur Respir J 2001, 17(6):1208-1215

21. Alton EW, Currie D, Logan-Sinclair R, Warner JO, Hodson ME, Geddes DM: Nasal potential difference: a clinical diagnostic test for cystic fibrosis. Eur Respir J 1990, 3(8):922-926.

22. Sauder RA, Chesrown SE, Loughlin GM: Clinical application of transepithelial potential difference measurements in cystic fibrosis. J Pediatr 1987, 111(3):353-358.

23. Middleton $P G$, House $H H$ : Measurement of airway ion transport assists the diagnosis of cystic fibrosis. Pediatr Pulmonol 2010, 45(8):789-795.

24. Wilschanski M, Dupuis A, Ellis L, Jarvi K, Zielenski J, Tullis E, Martin S, Corey $M$, Tsui LC, Durie P: Mutations in the cystic fibrosis transmembrane regulator gene and in vivo transepithelial potentials. Am J Respir Crit Care Med 2006, 174(7):787-794.

25. Walker LC, Venglarik CJ, Aubin G, Weatherly MR, McCarty NA, Lesnick B, Ruiz F, Clancy JP, Sorscher EJ: Relationship between airway ion transport and a mild pulmonary disease mutation in CFTR. Am J Respir Crit Care Med 1997, 155(5):1684-1689.

26. Bronsveld I, Mekus F, Bijman J, Ballmann M, de Jonge HR, Laabs U, Halley DJ, Ellemunter H, Mastella G, Thomas S, Veeze HJ, Tummler B: Chloride conductance and genetic background modulate the cystic fibrosis phenotype of Delta F508 homozygous twins and siblings. J Clin Invest 2001, 108(11):1705-1715

27. Leal T, Fajac I, Wallace HL, Lebecque P, Lebacq J, Hubert D, Dall'Ava J, Dusser D, Ganesan AP, Knoop C, Cumps J, Wallemacq P, Southern KW: Airway ion transport impacts on disease presentation and severity in cystic fibrosis. Clin Biochem 2008, 41(10-11):764-772.

28. Wallace HL, Barker PM, Southern KW: Nasal airway ion transport and lung function in young people with cystic fibrosis. Am J Respir Crit Care Med 2003, 168(5):594-600.

29. Naehrlich L, Ballmann M, Davies J, Derichs N, Gonska T, Hjelte L, van Konigsbruggen-Rietschel S, Leal T, Melotti P, Middleton P, Tummler B, Vermeulen F, Wilschanski M: Nasal potential difference measurements in diagnosis of cystic fibrosis: An international survey. J Cyst Fibros 2014, 13(1):24-28.

30. Sermet-Gaudelus I, Girodon E, Sands D, Stremmler N, Vavrova V, Deneuville E, Reix P, Bui S, Huet F, Lebourgeois M, Munck A, Iron A, Skalicka V, Bienvenu T, Roussel D, Lenoir G, Bellon G, Sarles J, Macek M, Roussey M, Fajac I, Edelman A: Clinical phenotype and genotype of children with borderline sweat test and abnormal nasal epithelial chloride transport. Am J Respir Crit Care Med 2010, 182(7):929-936.

31. Veeze HJ, Halley DJ, Bijman J, de Jongste JC, de Jonge HR, Sinaasappel M: Determinants of mild clinical symptoms in cystic fibrosis patients. Residual chloride secretion measured in rectal biopsies in relation to the genotype. J Clin Invest 1994, 93(2):461-466.

32. De Jonge HR, Ballmann M, Veeze H, Bronsveld I, Stanke F, Tummler B, Sinaasappel $\mathrm{M}$ : Ex vivo $\mathrm{CF}$ diagnosis by intestinal current measurements (ICM) in small aperture, circulating Ussing chambers. J Cyst Fibros 2004, 3(Suppl 2):159-163.

33. Veeze HJ, Sinaasappel M, Bijman J, Bouquet J, de Jonge HR: Ion transport abnormalities in rectal suction biopsies from children with cystic fibrosis. Gastroenterology 1991, 101(2):398-403.

34. Clancy JP, Szczesniak RD, Ashlock MA, Ernst SE, Fan L, Hornick DB, Karp PH Khan U, Lymp J, Ostmann AJ, Rezayat A, Starner TD, Sugandha SP, Sun H, Quinney N, Donaldson SH, Rowe SM, Gabriel SE: Multicenter intestinal current measurements in rectal biopsies from CF and non-CF subjects to monitor CFTR function. PLoS One 2013, 8(9):e73905.

35. Hogenauer C, Santa Ana CA, Porter UL, Millard M, Gelfand A, Rosenblatt RL, Prestidge CB, Fordtran JS: Active intestinal chloride secretion in human carriers of cystic fibrosis mutations: an evaluation of the hypothesis that heterozygotes have subnormal active intestinal chloride secretion. Am J Hum Genet 2000, 67(6):1422-1427.

36. Kalin N, Claass A, Sommer M, Puchelle E, Tummler B: DeltaF508 CFTR protein expression in tissues from patients with cystic fibrosis. $J$ Clin Invest 1999, 103(10):1379-1389. 
37. van Meegen MA, Terheggen-Lagro SW, Koymans KJ, van der Ent CK, Beekman $J M$ : Apical CFTR expression in human nasal epithelium correlates with lung disease in cystic fibrosis. PLoS One 2013, 8(3):e57617.

38. van Barneveld A, Stanke F, Tamm S, Siebert B, Brandes G, Derichs N, Ballmann M, Junge S, Tummler B: Functional analysis of F508del CFTR in native human colon. Biochim Biophys Acta 2010, 1802(11):1062-1069.

39. Greger R: Role of CFTR in the colon. Annu Rev Physiol 2000, 62:467-491.

40. Chilvers MA, McKean M, Rutman A, Myint BS, Silverman M, O'Callaghan C: The effects of coronavirus on human nasal ciliated respiratory epithelium. Eur Respir J 2001, 18(6):965-970.

41. Yeo NK, Jang YJ: Rhinovirus infection-induced alteration of tight junction and adherens junction components in human nasal epithelial cells. Laryngoscope 2010, 120(2):346-352.

42. Brezillon S, Dupuit F, Hinnrasky J, Marchand V, Kalin N, Tummler B, Puchelle E: Decreased expression of the CFTR protein in remodeled human nasal epithelium from non-cystic fibrosis patients. Lab Invest 1995, 72(2):191-200.

43. Knowles M, Murray G, Shallal J, Askin F, Ranga V, Gatzy J, Boucher R: Bioelectric properties and ion flow across excised human bronchi. J Appl Physiol 1984, 56(4):868-877.

44. Servidoni MF, Sousa M, Vinagre AM, Cardoso SR, Ribeiro MA, Meirelles LR, de Carvalho RB, Kunzelmann K, Ribeiro AF, Ribeiro JD, Amaral MD: Rectal forceps biopsy procedure in cystic fibrosis: technical aspects and patients perspective for clinical trials feasibility. BMC Gastroenterol 2013, 13(1):91.

doi:10.1186/1471-2466-14-156

Cite this article as: Bagheri-Hanson et al: Intestinal current measurement versus nasal potential difference measurements for diagnosis of cystic fibrosis: a case-control study. BMC Pulmonary Medicine 2014 14:156.

\section{Submit your next manuscript to BioMed Central and take full advantage of:}

- Convenient online submission

- Thorough peer review

- No space constraints or color figure charges

- Immediate publication on acceptance

- Inclusion in PubMed, CAS, Scopus and Google Scholar

- Research which is freely available for redistribution 